\title{
Surgical treatment of liver metastasis of gastric cancer: a retrospective multicenter cohort study (KSCC1302)
}

\author{
Eiji Oki $^{1} \cdot$ Shoji Tokunaga ${ }^{2}$ Y Yasunori Emi ${ }^{3} \cdot$ Tetsuya Kusumoto $^{4} \cdot$ \\ Manabu Yamamoto ${ }^{5} \cdot$ Kengo Fukuzawa $^{6} \cdot$ Ikuo Takahashi $^{7}$. \\ Sumiya Ishigami $^{8} \cdot$ Akihito Tsuji $^{9}$ Hidefumi Higashi ${ }^{10}$ - Toshihiko Nakamuraa ${ }^{11}$ \\ Hiroshi Saeki ${ }^{1} \cdot$ Ken Shirabe $^{1} \cdot$ Yoshihiro Kakeji $^{12} \cdot$ Kenji Sakai $^{13}$ • \\ Hideo Baba ${ }^{14}$ - Tadashi Nishimaki ${ }^{15}$ - Shoji Natsugoe ${ }^{8}$ - Yoshihiko Maehara ${ }^{1}$. \\ Kyushu Study Group of Clinical Cancer
}

Received: 26 April 2015/Accepted: 28 July 2015/Published online: 11 August 2015

(c) The International Gastric Cancer Association and The Japanese Gastric Cancer Association 2015

\begin{abstract}
Background The necessity of surgical treatment of liver metastases of gastric cancer is still controversial.

Patients and methods We conducted a multicenter retrospective cohort study of liver-limited metastasis of gastric cancer treated surgically between 2000 and 2010. In this study, 103 patients were registered, with nine patients excluded from the analysis as they did not meet the eligibility criteria.
\end{abstract}

Electronic supplementary material The online version of this article (doi:10.1007/s10120-015-0530-z) contains supplementary material, which is available to authorized users.

\section{Eiji Oki}

okieiji@surg2.med.kyushu-u.ac.jp

1 Department of Surgery and Science, Graduate School of Medical Sciences, Kyushu University, 3-1-1 Maidashi, Higashi-ku, Fukuoka, Fukuoka 812-8582, Japan

2 Medical Information Center, Kyushu University Hospital, Fukuoka, Japan

3 Department of Surgery, Saiseikai Fukuoka General Hospital, Fukuoka, Japan

4 Department of Gastroenterological Surgery/Clinical Research Institute Cancer Research Division, National Kyushu Medical Center, Fukuoka, Japan

5 Department of Gastroenterological Surgery, National Kyushu Cancer Center, Fukuoka, Japan

6 Department of Surgery, Oita Red Cross Hospital, Oita, Japan

7 Department of Surgery, Matsuyama Red Cross Hospital, Matsuyama, Japan

8 Department of Digestive Surgery, Breast and Thyroid Surgery, Graduate School of Medical and Dental Sciences, Kagoshima University, Kagoshima, Japan
Results Of the 94 patients, 69 underwent surgical resection, 11 underwent surgical resection combined with radiofrequency ablation or microwave coagulation therapy for small or deep tumors, and 14 underwent radiofrequency ablation or microwave coagulation therapy only. Synchronous and metachronous metastases were found in 37 and 57 patients, respectively. The 3- and 5-year overall survival rates of all the patients were 51.4 and $42.3 \%$, respectively. The 3- and 5-year relapse-free survival rates were 29.2 and $27.7 \%$, respectively. No significant difference in prognosis was observed between the patients who underwent surgical resection and those who underwent ablation therapy. The patients with hepatic solitary lesions

9 Department of Medical Oncology, Kobe City Medical Center General Hospital, Kobe, Japan

10 Department of Surgery, Steel Memorial Yawata Hospital, Kitakyushu, Japan

11 Department of Surgery, Kyushu Central Hospital of the Mutual Aid Association of Public School Teachers, Fukuoka, Japan

12 Division of Gastrointestinal Surgery, Department of Surgery, Kobe University Graduate School of Medicine, Kobe, Japan

13 Department of Medical Oncology, Saiseikai Kumamoto Hospital, Kumamoto, Japan

14 Department of Gastroenterological Surgery, Graduate School of Medical Sciences, Kumamoto University, Kumamoto, Japan

15 Division of Digestive and General Surgery, Faculty of Medicine, University of the Ryukyus, Okinawa, Japan 
and low-grade lymph node metastases of primary gastric cancer had significantly better overall survival and relapsefree survival.

Conclusions To our knowledge, this study is the largest series and first multicenter cohort study of liver-limited metastasis of gastric cancer. The study indicated that patients with a single liver metastasis with a grade lower than $\mathrm{N} 2$ lymph node metastasis of the primary lesion are the best candidates for liver resection.

Keywords Gastric cancer - Hepatectomy Radiofrequency ablation $\cdot$ Liver metastasis

\section{Introduction}

Gastric cancer, the commonest malignant tumor arising in the gastrointestinal tract, is the second leading cause of cancer-related death worldwide [1]. Recently, treatment of gastric cancer has improved drastically, and the 5-year survival rate of patients with T1 tumors exceeds $95 \%$ [2]. By contrast, the prognosis of patients with stage IV disease represented by peritoneal and liver metastases, which are para-aortic lymph node cases, is extremely poor, with a 3 -year survival rate lower than $10 \%[3,4]$.

The necessity of surgical removal of liver metastases of gastric cancer is still controversial. Liver metastasis of gastric cancer is categorized as stage IV disease, regardless of the number of metastases, in the Japanese Classification of Gastric Carcinoma [5]. The guidelines do not recommend surgery for stage IV gastric cancer; therefore, most patients with liver metastases of gastric cancer receive palliative treatment. According to the National Comprehensive Cancer Network guidelines, surgical therapy is not recommended. Liver metastasis of gastric cancer is defined as stage IVb disease, for which systemic therapy is recommended [6, 7]. By contrast, colorectal liver metastases are widely considered as targets of surgery with an intent to cure because they often present as liver-only diseases, and $\mathrm{R} 0$ resection showed favorable survival in a recent clinical study [8]. Recently, the Guidelines Committee of the Japan Gastric Cancer Association reconsidered the treatment of potentially resectable M1 disease [9], on the basis of a report that showed favorable results in resectable liver metastases [10-20]. Therefore, the importance of liver resection for liver metastasis must be thoroughly analyzed. Many retrospective case-control studies of liver metastasis from gastric cancer have been reported $[10-13,15,17,18$, 21-26]. These analyses are presented from a single center, have a small number of cases, and include old cases from the 1970s and 1980s [10, 12, 13, 15]. No clinical trials or even cohort studies have been conducted on chemotherapy for liver-limited metastasis (LLM) from gastric cancer.
This report is the first multicenter cohort study of LLM treated surgically between 2000 and 2010 .

\section{Methods}

\section{Patient population and data collection}

Between September 2013 and September 2014, 103 patients with LLMs of gastric cancer treated with surgery, microwave coagulation therapy (MCT), or radiofrequency ablation (RFA) were identified from 28 institutions in the Kyushu Study Group of Clinical Cancer in Japan.

The inclusion criteria for gastric cancer with liver metastasis were as follows: (1) histologically confirmed primary gastric cancer; (2) presence of synchronous or metachronous liver metastasis; and (3) surgical therapy, including liver resection, RFA, or MCT, performed between January 1, 2000 and December 31, 2010. Patients with metastasis other than liver metastasis, or with synchronous or metachronous double cancer were excluded. The ethical, medical, and scientific aspects of the study were reviewed and approved by the institutional review board of each participating institution. This trial was registered in the University Hospital Medical Information Network (UMIN) Clinical Trials Registry (UMIN000001340). The study was conducted in accordance with the Declaration of Helsinki of 1975, revised in 2000. Clinicopathology data were collected for each patient, including sex, age, carcinoembryonic antigen level, and information on the original gastric cancer. We used the 13th edition of the Japanese Classification of Gastric Carcinoma, used in Japan until 2011, for data management [27]. The number, size, and distribution of hepatic tumors and the details of chemotherapy for liver metastasis were investigated. The date of the last follow-up and the vital status were collected for all the patients.

\section{Statistical considerations}

Univariate and multivariate analyses (forward-stepwise selection procedure) were performed by Cox proportional hazards regression to identify risk factors that affect overall survival (OS) and recurrence-free survival (RFS). The significance levels for removal from and addition to the model were set at 0.20 and 0.10 , respectively. We conducted sensitivity analysis for the model selection by maximizing Akaike's information criterion (AIC) [28]. AIC is a measure for comparing maximum-likelihood models, to which the Cox proportional hazards model belongs. AIC is expressed as $-2 \log$ (likelihood) $+2 k$, where $k$ is the number of parameters estimated. OS was defined as the period from surgical therapy for liver 
metastasis to the date of death from any cause. RFS was defined as the period from surgical therapy for liver metastasis to the date of disease progression or death, whichever occurred first. If neither event occurred by the time of the last record, the patient was censored at that time. Factors included in the model were age, sex, Eastern Cooperative Oncology Group performance status, treatment method (surgery, RFA, and MCT), pathological diagnosis of primary gastric cancer (histological type, lymphatic invasion, venous invasion, lymph node metastasis), number of liver metastases, maximum tumor size of the liver metastasis, interval from primary diagnosis to liver metastasis treatment (synchronous or metachronous), and adjuvant chemotherapy. A two-sided $P<0.05$ was considered statistically significant. All statistical analyses were performed with Stata version 13 statistical analysis software (Stata, College Station, TX, USA).

\section{Results}

\section{Patient characteristics}

The study flowchart and baseline patient characteristics are presented in Fig. 1 and Table 1, respectively. Nine patients were excluded from the analysis because their treatment period did not match the eligibility criteria; thus, 94 patients were analyzed. Of the 94 patients, 69 (70.2\%) underwent surgical resection and $11(11.7 \%)$ underwent surgery with MCT/RFA. Fourteen patients $(14.9 \%)$ were treated with MCT/RFA only. Synchronous and metachronous metastases were found in 37 patients $(39.4 \%)$ and 57

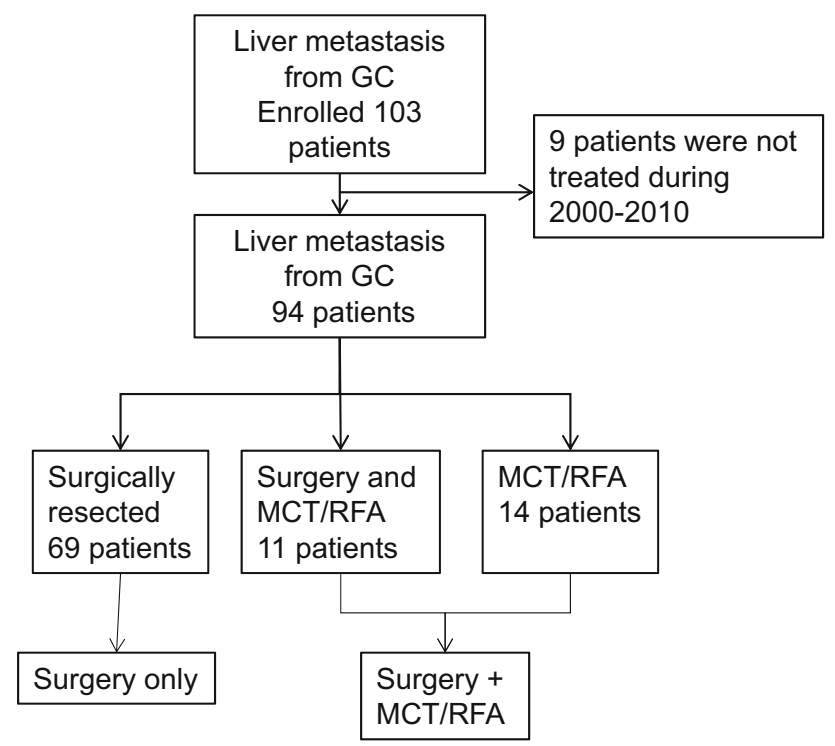

Fig. 1 Flowchart for the cohort study. $G C$ gastric cancer, $M C T$ microwave coagulation therapy, $R F A$ radiofrequency ablation
Table 1 Baseline patient characteristics

\begin{tabular}{|c|c|}
\hline Variable & Value \\
\hline \multicolumn{2}{|l|}{ Age } \\
\hline Median (range) & $70(39-86)$ years \\
\hline \multicolumn{2}{|l|}{ Sex } \\
\hline Male & $75(79.8 \%)$ \\
\hline Female & $19(20.2 \%)$ \\
\hline \multicolumn{2}{|l|}{ Position of gastric cancer } \\
\hline Upper & $21(22.3 \%)$ \\
\hline Middle & $26(27.7 \%)$ \\
\hline Lower & $42(44.7 \%)$ \\
\hline Unknown & $5(5.3 \%)$ \\
\hline \multicolumn{2}{|l|}{ Histological type } \\
\hline Intestinal & $65(69.1 \%)$ \\
\hline Diffuse & $26(27.7 \%)$ \\
\hline Unknown & $3(3.2 \%)$ \\
\hline \multicolumn{2}{|l|}{ Metachronous/synchronous } \\
\hline Metachronous & $57(60.6 \%)$ \\
\hline Synchronous & $37(39.4 \%)$ \\
\hline \multicolumn{2}{|l|}{ Preoperative chemotherapy } \\
\hline Not performed & $73(77.7 \%)$ \\
\hline Performed & $21(22.3 \%)$ \\
\hline \multicolumn{2}{|l|}{ Type of surgical treatment } \\
\hline Surgery only & $69(70.2 \%)$ \\
\hline Surgery plus MCT or RFA & $25(29.8 \%)$ \\
\hline \multicolumn{2}{|l|}{ Number of metastases } \\
\hline 1 & $56(59.6 \%)$ \\
\hline 2 & $19(20.2 \%)$ \\
\hline 3 & $9(9.6 \%)$ \\
\hline$>4$ & $10(10.6 \%)$ \\
\hline \multicolumn{2}{|l|}{ Postoperative chemotherapy } \\
\hline Not performed & $29(30.9 \%)$ \\
\hline Performed & $65(69.1 \%)$ \\
\hline
\end{tabular}

$M C T$ microwave coagulation therapy, $R F A$ radiofrequency ablation

patients $(60.6 \%)$, respectively. Single and multiple liver metastases were found in 56 patients $(59.6 \%)$ and 38 patients (40.4\%), respectively. Fifty-one patients (54.3\%) had a maximum tumor size greater than $3 \mathrm{~cm}$. Chemotherapy was prescribed after liver surgery or ablation in 65 patients $(69.1 \%)$.

\section{Patient outcomes}

The median follow-up time was 24.7 months (range 0.3-141.8 months). The 1-, 3-, and 5-year OS rates after surgery were $86.5,51.4$, and $42.1 \%$, respectively (Fig. 2a), with a median OS of 3.396 years [95\% confidence interval (CI) 2.036-9.160]. The 1-, 3-, and 5-year RFS rates were $48.4,29.2$, and $27.7 \%$, respectively, with a median RFS of 0.977 years $(95 \%$ CI $0.649-1.554 ; \quad$ Fig. $2 b)$. In a 

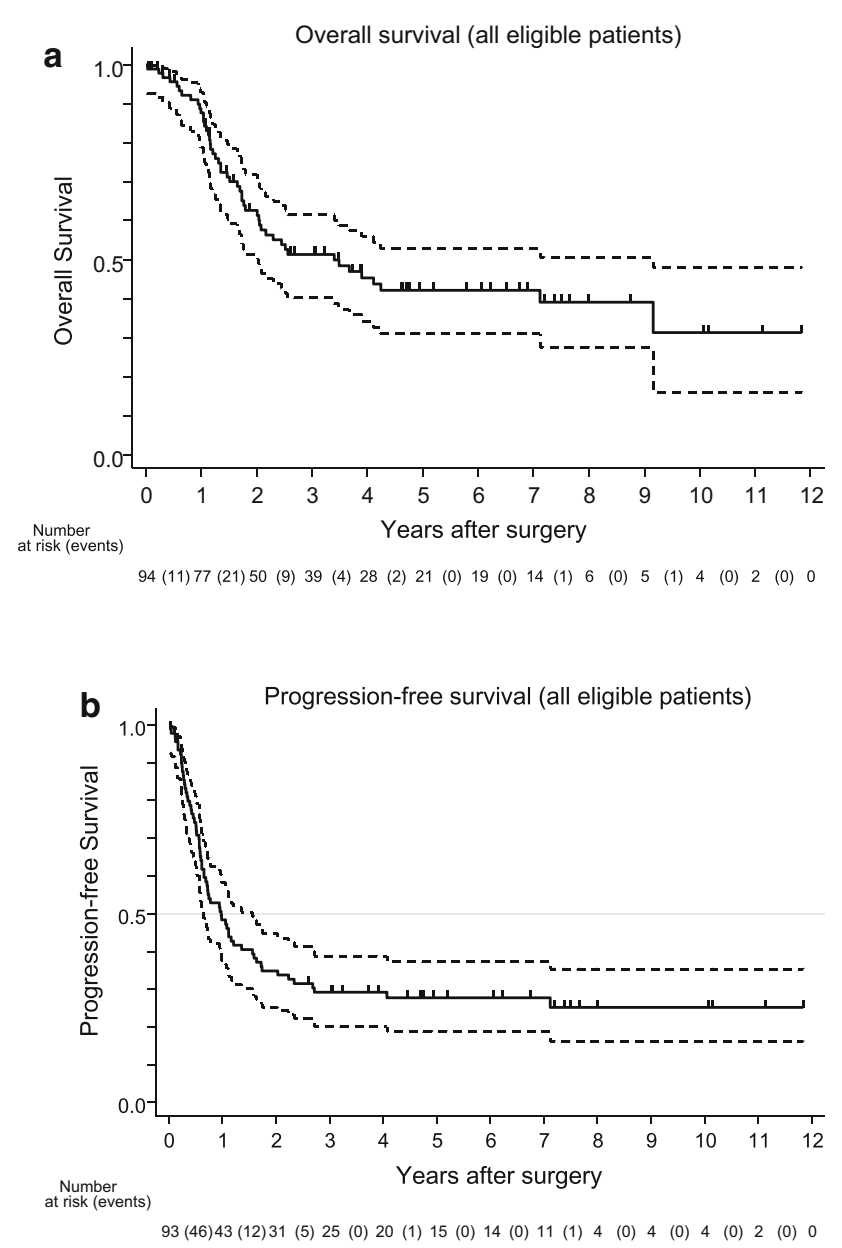

Fig. 2 a Overall survival of all the eligible patients. The dotted lines represent the $95 \%$ confidence limits. b Progression-free survival of all the eligible patients. The dotted lines represent the $95 \%$ confidence limits.

univariate analysis, significant differences in OS and RFS were observed between the patients with solitary hepatic lesions [Tables 2, 3; hazard ratio (HR) 2.49; $95 \%$ CI $1.41-4.41 ; P=0.001]$ and those with multiple hepatic lesions (HR 2.04; $95 \%$ CI $1.25-3.33 ; \quad P=0.004$; Tables 2, 3, Fig. 3). Significant differences in OS and RFS were also observed between the patients with N0/N1 lymph node metastasis of primary gastric cancer (HR 2.64; $95 \%$ CI 1.49-4.69; $P<0.001$; Tables 2, 3) and those with N2/ N3 lymph node metastasis (HR 2.64; $95 \%$ CI 1.58-4.41; $P<0.001$; Tables 2, 3, Fig. S1). Larger tumors tended to lead to poorer survival, but this was not significant. Ablation therapy, including RFA and MCT, did not significantly affect survival (Fig. S2). Chemotherapy was administered to 65 patients after surgery. Progression-free survival (PFS) of the patients who received chemotherapy after liver surgery or ablation was worse than that of the patients who did not receive chemotherapy. The median OS of the patients who received chemotherapy after liver surgery was
3.40 years, but that of the patients who did not receive chemotherapy did not reach the median value (Fig. S3). A multivariate model was selected from the following ten parameters: sex, histological type, lymphatic invasion, venous invasion, tumor invasion, lymph node metastasis, metachronous/synchronous metastasis, number of metastases, maximum size of the metastatic tumor, and type of surgical treatment. Single metastatic tumors (HR 2.14, $95 \%$ CI 1.16-3.97), the extent of lymph node metastasis (HR 2.16, $95 \%$ CI 1.16-4.02), and the maximum tumor size (HR 1.62, $95 \%$ CI 0.90-2.90) were selected by the stepwise method. The same model was chosen by minimization of AIC. They were identified as independent predictive factors of poor prognosis (Table 4).

\section{Discussion}

Standard care and treatment options for liver metastasis of gastric cancer have not been determined, as LLM of gastric cancer is rare and not often reported. To date, many case series have emphasized the importance of surgical treatment. However, these reports have shown only the experiences of single institutions in small case studies. Therefore, caution is needed when one is making direct comparisons of results between previous studies and our study as the characteristics of the patients in these studies differ. The benefits of modern surgery and chemotherapy have not been properly evaluated, as medicine has improved greatly within the last decade. To improve patient care, it is necessary to understand the impact of surgical treatment of LLM of gastric cancer in the context of the latest clinical advances. Therefore, we conducted a multicenter cohort study of LLM of gastric cancers.

Our multicenter cohort study revealed some important results. First, the 5-year OS and RFS of all the patients were 42.1 and $27.7 \%$, respectively. The median OS and RFS were 3.40 years ( 40.8 months) and 0.94 years (11.3 months), respectively. The median OS of the latest phase III clinical trials in stage IV gastric cancer is 9.5-14.1 months [3, 29-32]. Our results strongly suggest that surgical treatment of liver metastasis should be considered when one is developing treatment plans for liver metastasis. It is also important to understand the patient subsets that are suitable for surgical treatment of LLM of gastric cancer. We found that the numbers of liver metastases and lymph node metastasis of the primary tumor were the most important independent prognostic factors. Some reports also suggested that patients with a single liver metastasis had significantly higher 3-year survival rates than those with multiple liver metastases [10, 33]. We analyzed the difference in prognosis of patients with different numbers of metastases (Fig. S4). The prognosis of 
Table 2 Univariate analysis of hazard ratios estimated by Cox regression (overall survival)

\begin{tabular}{|c|c|c|c|c|}
\hline & Number & Hazard ratio & $95 \% \mathrm{CI}$ & $P$ \\
\hline \multicolumn{5}{|l|}{ Sex } \\
\hline Male & 75 & 1.00 & & \\
\hline Female & 19 & 2.00 & $1.05-3.81$ & 0.034 \\
\hline \multicolumn{5}{|l|}{ Age (years) } \\
\hline$<70$ & 44 & 1.00 & & \\
\hline$\geq 70$ & 50 & 1.11 & $0.63-1.94$ & 0.73 \\
\hline \multicolumn{5}{|l|}{ Position of tumor } \\
\hline Upper & 21 & 1.00 & & \\
\hline Middle & 26 & 0.71 & $0.33-1.54$ & 0.39 \\
\hline Lower & 42 & 0.75 & $0.37-1.52$ & 0.43 \\
\hline Unknown & 5 & 0.31 & $0.04-2.37$ & 0.26 \\
\hline \multicolumn{5}{|l|}{ Histological type } \\
\hline Intestinal & 65 & 1.00 & & \\
\hline Diffuse & 26 & 1.80 & $1.00-3.25$ & 0.052 \\
\hline \multicolumn{5}{|l|}{ Lymphatic invasion } \\
\hline Iy0 & 21 & 1.00 & & \\
\hline ly $1 / 1 y 2 / l y 3$ & 66 & 1.19 & $0.67-2.73$ & 0.40 \\
\hline \multicolumn{5}{|l|}{ Venous invasion } \\
\hline v0 & 16 & 1.00 & & \\
\hline $\mathrm{v} 1 / \mathrm{v} 2 / \mathrm{v} 3$ & 71 & 0.91 & $0.42-1.96$ & 0.81 \\
\hline \multicolumn{5}{|l|}{ Tumor invasion } \\
\hline $\mathrm{T} 0+\mathrm{T} 1(\mathrm{M})+\mathrm{T} 1(\mathrm{SM})$ & 8 & 1.00 & & \\
\hline $\mathrm{T} 2(\mathrm{MP})+\mathrm{T} 2(\mathrm{SS})$ & 56 & 0.86 & $0.30-2.47$ & 0.78 \\
\hline $\mathrm{T} 3(\mathrm{SE})+\mathrm{T} 4(\mathrm{SI})$ & 30 & 1.02 & $0.34-3.05$ & 0.97 \\
\hline \multicolumn{5}{|l|}{ Lymph node metastasis } \\
\hline $\mathrm{N} 0+\mathrm{N} 1$ & 67 & 1.00 & & \\
\hline $\mathrm{N} 2+\mathrm{N} 3$ & 27 & 2.64 & $1.49-4.69$ & $<0.001$ \\
\hline \multicolumn{5}{|l|}{ Metachronous/synchronous } \\
\hline Metachronous & 57 & 1.00 & & \\
\hline Synchronous & 37 & 1.25 & $0.71-2.19$ & 0.44 \\
\hline \multicolumn{5}{|l|}{ Number of metastases } \\
\hline 1 & 56 & 1.00 & & \\
\hline$>1$ & 38 & 2.49 & $1.41-4.41$ & 0.002 \\
\hline \multicolumn{5}{|c|}{ Maximum size of the metastatic tumor $(\mathrm{cm})$} \\
\hline$<3$ & 41 & 1.00 & & \\
\hline$\geq 3$ & 51 & 1.33 & $0.75-2.37$ & 0.33 \\
\hline \multicolumn{5}{|l|}{ Type of surgical treatment } \\
\hline Surgery & 69 & 1.00 & & \\
\hline Surgery/MCT/RFA & 25 & 1.50 & $0.83-2.71$ & 0.18 \\
\hline \multicolumn{5}{|l|}{ Resectability } \\
\hline R0 & 66 & 1.00 & & \\
\hline $\mathrm{R} 1+\mathrm{R} 2$ & 28 & 1.75 & $0.99-3.10$ & 0.055 \\
\hline \multicolumn{5}{|l|}{ Postoperative complications } \\
\hline No & 60 & 1.00 & & \\
\hline Yes & 16 & 1.07 & $0.51-2.25$ & 0.85 \\
\hline \multicolumn{5}{|l|}{ Postoperative chemotherapy } \\
\hline Not performed & 29 & 1.00 & & \\
\hline Performed & 65 & 1.10 & $0.56-2.15$ & 0.79 \\
\hline
\end{tabular}

$C I$ confidence interval, $M$ mucosa, $M C T$ microwave coagulation therapy, $M P$ muscularis propria, $R F A$ radiofrequency ablation, $S E$ serosa, $S I$ adjacent structures, $S M$ submucosa, $S S$ subserosa 
Table 3 Univariate analysis of hazard ratios estimated by Cox regression (progression-free survival)

\begin{tabular}{|c|c|c|c|c|}
\hline & Number & Hazard ratio & $95 \% \mathrm{CI}$ & $P$ \\
\hline \multicolumn{5}{|l|}{ Sex } \\
\hline Male & 75 & 1.00 & & \\
\hline Female & 19 & 1.89 & $1.07-3.34$ & 0.028 \\
\hline \multicolumn{5}{|l|}{ Age (years) } \\
\hline$<70$ & 44 & 1.00 & & \\
\hline$\geq 70$ & 50 & 0.76 & $0.47-1.24$ & 0.28 \\
\hline \multicolumn{5}{|l|}{ Position of tumor } \\
\hline Upper & 21 & 1.00 & & \\
\hline Middle & 26 & 1.17 & $0.61-2.25$ & 0.63 \\
\hline Lower & 42 & 0.80 & $0.43-1.49$ & 0.48 \\
\hline Unknown & 5 & 0.24 & $0.03-1.84$ & 0.17 \\
\hline \multicolumn{5}{|l|}{ Histological type } \\
\hline Intestinal & 65 & 1.00 & & \\
\hline Diffuse & 26 & 1.83 & $1.09-3.08$ & 0.023 \\
\hline \multicolumn{5}{|l|}{ Lymphatic invasion } \\
\hline Iy0 & 21 & 1.00 & & \\
\hline ly $1 / 1 y 2 / l y 3$ & 66 & 1.42 & $0.75-2.67$ & 0.28 \\
\hline \multicolumn{5}{|l|}{ Venous invasion } \\
\hline v0 & 16 & 1.00 & & \\
\hline $\mathrm{v} 1 / \mathrm{v} 2 / \mathrm{v} 3$ & 71 & 1.32 & $0.67-2.61$ & 0.42 \\
\hline \multicolumn{5}{|l|}{ Tumor invasion } \\
\hline $\mathrm{T} 0+\mathrm{T} 1(\mathrm{M})+\mathrm{T} 1(\mathrm{SM})$ & 8 & 1.00 & & \\
\hline $\mathrm{T} 2(\mathrm{MP})+\mathrm{T} 2(\mathrm{SS})$ & 56 & 1.03 & $0.41-2.62$ & 0.95 \\
\hline $\mathrm{T} 3(\mathrm{SE})+\mathrm{T} 4(\mathrm{SI})$ & 30 & 1.11 & $0.42-2.95$ & 0.83 \\
\hline \multicolumn{5}{|l|}{ Lymph node metastasis } \\
\hline $\mathrm{N} 0+\mathrm{N} 1$ & 67 & 1.00 & & \\
\hline $\mathrm{N} 2+\mathrm{N} 3$ & 27 & 2.64 & $1.58-4.41$ & $<0.001$ \\
\hline \multicolumn{5}{|l|}{ Metachronous/synchronous } \\
\hline Metachronous & 57 & 1.00 & & \\
\hline Synchronous & 37 & 1.67 & $1.02-2.72$ & 0.040 \\
\hline \multicolumn{5}{|l|}{ Number of metastases } \\
\hline 1 & 56 & 1.00 & & \\
\hline$>1$ & 38 & 2.04 & $1.25-3.33$ & 0.005 \\
\hline \multicolumn{5}{|c|}{ Maximum size of the metastatic tumor $(\mathrm{cm})$} \\
\hline$<3$ & 41 & 1.00 & & \\
\hline$\geq 3$ & 51 & 1.26 & $0.76-2.07$ & 0.37 \\
\hline \multicolumn{5}{|l|}{ Type of surgical treatment } \\
\hline Surgery & 69 & 1.00 & & \\
\hline Surgery/MCT/RFA & 25 & 1.62 & $0.95-2.77$ & 0.08 \\
\hline \multicolumn{5}{|l|}{ Resectability } \\
\hline R0 & 66 & 1.00 & & \\
\hline $\mathrm{R} 1+\mathrm{R} 2$ & 28 & 1.73 & $1.04-2.90$ & 0.036 \\
\hline \multicolumn{5}{|l|}{ Postoperative complications } \\
\hline No & 60 & 1.00 & & \\
\hline Yes & 16 & 0.85 & $0.44-1.65$ & 0.64 \\
\hline \multicolumn{5}{|l|}{ Postoperative chemotherapy } \\
\hline Not performed & 29 & 1.00 & & \\
\hline Performed & 65 & 1.63 & $0.89-3.00$ & 0.12 \\
\hline
\end{tabular}

$C I$ confidence interval, $M$ mucosa, $M C T$ microwave coagulation therapy, $M P$ muscularis propria, $R F A$ radiofrequency ablation, $S E$ serosa, $S I$ adjacent structures, $S M$ submucosa, $S S$ subserosa 


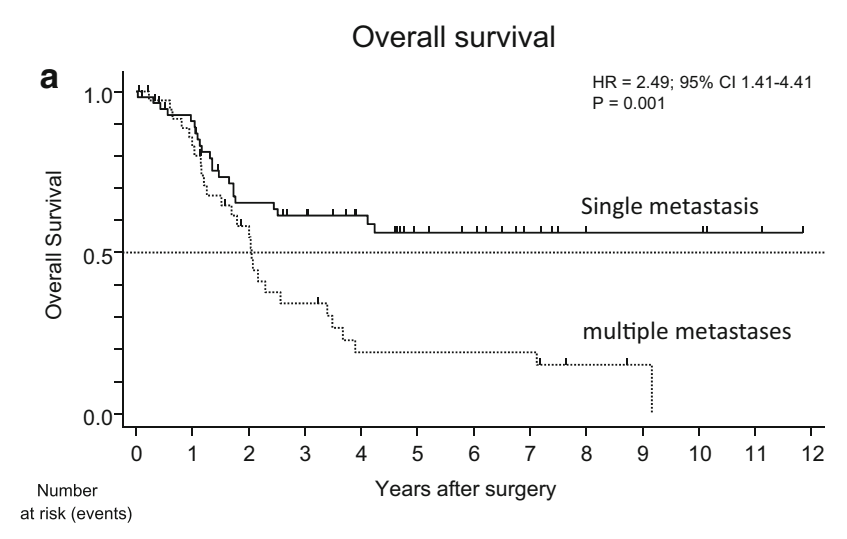

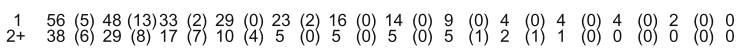

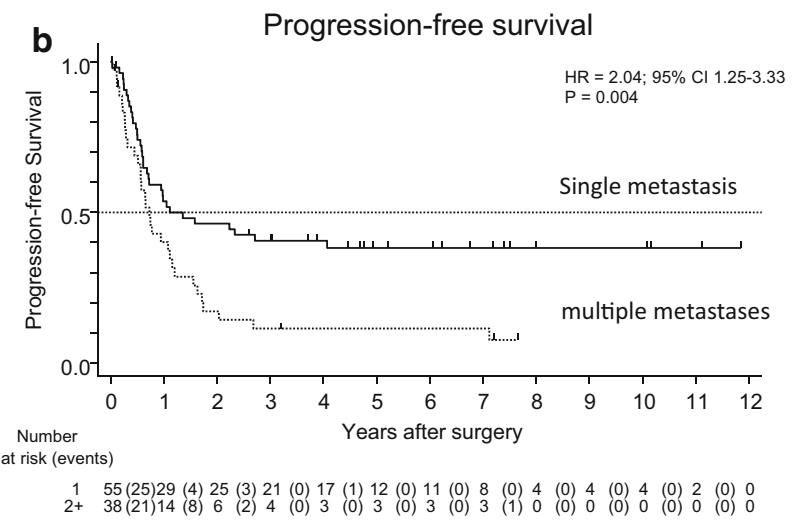

Fig. 3 a Overall survival of patients with a single metastasis (solid line) and multiple metastases (dotted line). b Progression-free survival of patients with a single metastasis (solid line) and multiple metastases (dotted line). CI confidence interval, $H R$ hazard ratio

Table 4 Multivariate analysis of hazard ratios selected by the stepwise method (overall survival)

\begin{tabular}{lll}
\hline Variables & Hazard ratio $(95 \% \mathrm{CI})$ & $P$ \\
\hline $\begin{array}{l}\text { Number of metastases } \\
1 \text { versus }>1\end{array}$ & $2.14(1.16-3.97)$ & 0.015 \\
$\begin{array}{l}\text { Lymph node metastasis } \\
\mathrm{N} 0+\mathrm{N} 1 \text { versus N2 }+\mathrm{N} 3\end{array}$ & $2.16(1.16-4.02)$ & 0.015 \\
$\begin{array}{l}\text { Maximum size of the tumor } \\
<3 \mathrm{~cm} \text { versus } \geq 3 \mathrm{~cm}\end{array}$ & $1.62(0.90-2.90)$ & 0.11 \\
\hline
\end{tabular}

CI confidence interval

patients with a single metastasis was better than that of patients with two or more metastases. Lymph node metastasis of the primary tumor was also revealed to be an independent prognostic factor. The differences in prognosis between each grade of lymph node metastasis are shown in Fig. S5. N0 and N1 lymph node metastases have an apparently better prognosis than $\mathrm{N} 2$ and $\mathrm{N} 3$ lymph node metastases. Therefore, we conclude that surgical treatment can be recommended only for a single NO/N1 metastasis.
The prognosis for LLM after surgery has been reported to be possibly influenced by many pathological features of the original gastric cancer, such as tumor invasion depth [20], lymphatic invasion, and venous invasion [16]. This study, however, did not find significant effects of these features on survival, except for lymph node metastasis of primary cancer.

Many chemotherapeutic protocols for gastric cancer have been investigated over the past decades, and some regimens have been shown to prolong the survival of patients with metastatic gastric cancer [3, 29, 31, 34]. In particular, 5-fluorouracil derivatives and cisplatin have been used as standard drugs for gastric cancer treatment since 2010 [3]. In our analysis, $69.1 \%$ of the patients were treated with chemotherapy after surgical treatment of liver metastasis, and $24.6 \%$ (16 of 65 patients) were treated with a combination of 5-fluorouracil derivatives and cisplatin. However, postoperative chemotherapy did not have a strong effect on OS (Fig. S2a). We did not find any effect of chemotherapy even in our analysis of the cases after 2006. One reason is that this is a retrospective cohort study and patients who received chemotherapy may have had aggressive metastasis. In fact, the chemotherapy group had more patients with multiple metastases. The PFS curves of the patients who received and the patients who did not receive chemotherapy after liver surgery were synchronized in the first year. However, the PFS curve of the chemotherapy group dropped rapidly after 1 year (Fig. S2b), whereas the OS of the patients who received postoperative chemotherapy was better in the first year. Chemotherapy might have prevented disease progression in the first year but could not control disease progression after 1 year. The patients who did not receive chemotherapy and had better prognostic factors such as a single metastasis and low-grade lymph node metastasis of the primary cancer may have longer survival. We could not conclusively determine the effects of chemotherapy after liver surgery in this cohort. Recent appropriate chemotherapy may be associated with improved survival.

To our knowledge, this study is the largest series on liver metastasis from gastric cancer. The study indicates that patients with a single liver metastasis with N0 or N1 lymph node metastasis of the primary lesion are the best candidates for liver resection. Although this was a retrospective observational study without a control group, these results could be helpful in designing treatment approaches for LLM of gastric cancer.

Acknowledgments We are grateful to the participating patients and their families. We are indebted to the physicians and all other medical staff. We also thank Ms. Sakamoto and the staff at the Clinical Research Support Center Kyushu (CReS Kyushu) for their excellent data collection and management, secretarial assistance, and support. This study was conducted by the Kyushu Study Group of Clinical 
Cancer and CReS Kyushu. Chugai Pharmaceutical, Yakult Honsha, Takeda Pharmaceutical, Merck Serono, and Taiho Pharmaceutical have provided an unrestricted contribution to CReS Kyushu.

\section{Compliance with ethical standards}

All procedures followed in this study were in accordance with the ethical standards of the responsible committee on human experimentation of each participating institution and with the 1964 and later versions of the Declaration of Helsinki.

Conflict of interest The authors declare that they have no conflict of interest.

\section{References}

1. Pisani P, Parkin DM, Bray F, Ferlay J. Estimates of the worldwide mortality from 25 cancers in 1990. Int $\mathrm{J}$ Cancer. 1999;83:18-29.

2. Yoshikawa T, Sasako M. Gastrointestinal cancer: adjuvant chemotherapy after D2 gastrectomy for gastric cancer. Nat Rev Clin Oncol. 2012;9:192-4.

3. Koizumi W, Narahara H, Hara T, Takagane A, Akiya T, Takagi M, Miyashita K, Nishizaki T, Kobayashi O, Takiyama W, Toh Y, Nagaie T, Takagi S, Yamamura Y, Yanaoka K, Orita H, Takeuchi M. S-1 plus cisplatin versus S-1 alone for first-line treatment of advanced gastric cancer (SPIRITS trial): a phase III trial. Lancet Oncol. 2008;9:215-21.

4. Boku N. Chemotherapy for metastatic gastric cancer in Japan. Int J Clin Oncol. 2008;13:483-7.

5. Japanese Gastric Cancer Association. Japanese classification of gastric carcinoma: 3rd English edition. Gastric Cancer 2011;14:101-12.

6. Strong VE, D'Amico TA, Kleinberg L, Ajani J. Impact of the 7th edition AJCC staging classification on the NCCN clinical practice guidelines in oncology for gastric and esophageal cancers. J Natl Compr Canc Netw. 2013;11:60-6.

7. Ajani JA, Bentrem DJ, Besh S, D'Amico TA, Das P, Denlinger C, Fakih MG, Fuchs CS, Gerdes H, Glasgow RE, Hayman JA, Hofstetter WL, Ilson DH, Keswani RN, Kleinberg LR, Korn WM, Lockhart AC, Meredith K, Mulcahy MF, Orringer MB, Posey JA, Sasson AR, Scott WJ, Strong VE, Varghese TK Jr, Warren G, Washington MK, Willett C, Wright CD, McMillian NR, Sundar H. Gastric cancer, version 2.2013: featured updates to the NCCN guidelines. J Natl Compr Canc Netw. 2013;11:531-46.

8. Folprecht G, Gruenberger T, Bechstein W, Raab HR, Weitz J, Lordick F, Hartmann JT, Stoehlmacher-Williams J, Lang H, Trarbach T, Liersch T, Ockert D, Jaeger D, Steger U, Suedhoff T, Rentsch A, Kohne CH. Survival of patients with initially unresectable colorectal liver metastases treated with FOLFOX/cetuximab or FOLFIRI/cetuximab in a multidisciplinary concept (CELIM study). Ann Oncol. 2014;25:1018-25.

9. Kodera Y, Fujitani K, Fukushima N, Ito S, Muro K, Ohashi N, Yoshikawa T, Kobayashi D, Tanaka C, Fujiwara M. Surgical resection of hepatic metastasis from gastric cancer: a review and new recommendation in the Japanese gastric cancer treatment guidelines. Gastric Cancer. 2014;17:206-12.

10. Okano K, Maeba T, Ishimura K, Karasawa Y, Goda F, Wakabayashi $\mathrm{H}$, Usuki $\mathrm{H}$, Maeta $\mathrm{H}$. Hepatic resection for metastatic tumors from gastric cancer. Ann Surg. 2002;235:86-91.

11. Saiura A, Umekita N, Inoue S, Maeshiro T, Miyamoto S, Matsui Y, Asakage M, Kitamura M. Clinicopathological features and outcome of hepatic resection for liver metastasis from gastric cancer. Hepatogastroenterology. 2002;49:1062-5.

12. Sakamoto Y, Ohyama S, Yamamoto J, Yamada K, Seki M, Ohta K, Kokudo N, Yamaguchi T, Muto T, Makuuchi M. Surgical resection of liver metastases of gastric cancer: an analysis of a 17-year experience with 22 patients. Surgery. 2003;133:507-11.

13. Shirabe K, Shimada M, Matsumata T, Higashi H, Yakeishi Y, Wakiyama S, Ikeda Y, Ezaki T, Fukuzawa S, Takenaka K, Kishikawa K, Ikeda T, Taguchi K, Maehara Y, Sugimachi K. Analysis of the prognostic factors for liver metastasis of gastric cancer after hepatic resection: a multi-institutional study of the indications for resection. Hepatogastroenterology. 2003;50:1560-3.

14. Roh HR, Suh KS, Lee HJ, Yang HK, Choe KJ, Lee KU. Outcome of hepatic resection for metastatic gastric cancer. Am Surg. 2005;71:95-9.

15. Koga R, Yamamoto J, Ohyama S, Saiura A, Seki M, Seto Y, Yamaguchi T. Liver resection for metastatic gastric cancer: experience with 42 patients including eight long-term survivors. Jpn J Clin Oncol. 2007;37:836-42.

16. Sakamoto Y, Sano T, Shimada K, Esaki M, Saka M, Fukagawa T, Katai H, Kosuge T, Sasako M. Favorable indications for hepatectomy in patients with liver metastasis from gastric cancer. J Surg Oncol. 2007;95:534-9.

17. Cheon SH, Rha SY, Jeung HC, Im CK, Kim SH, Kim HR, Ahn JB, Roh JK, Noh SH, Chung HC. Survival benefit of combined curative resection of the stomach (D2 resection) and liver in gastric cancer patients with liver metastases. Ann Oncol. 2008;19:1146-53.

18. Thelen A, Jonas S, Benckert C, Lopez-Hanninen E, Neumann U, Rudolph B, Schumacher G, Neuhaus P. Liver resection for metastatic gastric cancer. Eur J Surg Oncol. 2008;34:1328-34.

19. Kakeji Y, Morita M, Maehara Y. Strategies for treating liver metastasis from gastric cancer. Surg Today. 2010;40:287-94.

20. Takemura N, Saiura A, Koga R, Arita J, Yoshioka R, Ono Y, Hiki N, Sano T, Yamamoto J, Kokudo N, Yamaguchi T. Long-term outcomes after surgical resection for gastric cancer liver metastasis: an analysis of 64 macroscopically complete resections. Langenbecks Arch Surg. 2012;397:951-7.

21. Ochiai T, Sasako M, Mizuno S, Kinoshita T, Takayama T, Kosuge T, Yamazaki S, Maruyama K. Hepatic resection for metastatic tumours from gastric cancer: analysis of prognostic factors. Br J Surg. 1994;81:1175-8.

22. Miyazaki M, Itoh $H$, Nakagawa $K$, Ambiru S, Shimizu $H$, Togawa A, Shiobara M, Ohtsuka M, Sasada K, Shimizu Y, Yoshioka S, Nakajima N, Suwa T, Kimura F. Hepatic resection of liver metastases from gastric carcinoma. Am J Gastroenterol. 1997;92:490-3.

23. Ambiru S, Miyazaki M, Ito H, Nakagawa K, Shimizu H, Yoshidome H, Shimizu Y, Nakajima N. Benefits and limits of hepatic resection for gastric metastases. Am J Surg. 2001;181:279-83.

24. Fujii K, Fujioka S, Kato K, Machiki Y, Kutsuna Y, Ishikawa A, Takamizawa J, Ko K, Yoshida K, Nimura Y. Resection of liver metastasis from gastric adenocarcinoma. Hepatogastroenterology. 2001;48:368-71.

25. Morise Z, Sugioka A, Hoshimoto S, Kato T, Ikeda M, Uyama I, Horiguchi A, Miyakawa S. The role of hepatectomy for patients with liver metastases of gastric cancer. Hepatogastroenterology. 2008;55:1238-41.

26. Choi SB, Song J, Kang CM, Hyung WJ, Kim KS, Choi JS, Lee WJ, Noh SH, Kim CB. Surgical outcome of metachronous hepatic metastases secondary to gastric cancer. Hepatogastroenterology. 2010;57:29-34.

27. Aikou T, Hokita S, Natsugoe S. Japanese classification of gastric carcinoma (the 13th edition, June 1999): points to be revised. Nihon Rinsho. 2001;59(Suppl 4):159-65. 
28. Akaike H. A new look at the statistical model identification. IEEE Trans Autom Control. 1974;19:716-23.

29. Bang YJ, Van Cutsem E, Feyereislova A, Chung HC, Shen L, Sawaki A, Lordick F, Ohtsu A, Omuro Y, Satoh T, Aprile G, Kulikov E, Hill J, Lehle M, Ruschoff J, Kang YK. Trastuzumab in combination with chemotherapy versus chemotherapy alone for treatment of HER2-positive advanced gastric or gastro-oesophageal junction cancer (ToGA): a phase 3, open-label, randomised controlled trial. Lancet. 2010;376:687-97.

30. Ohtsu A, Shah MA, Van Cutsem E, Rha SY, Sawaki A, Park SR, Lim HY, Yamada Y, Wu J, Langer B, Starnawski M, Kang YK. Bevacizumab in combination with chemotherapy as first-line therapy in advanced gastric cancer: a randomized, double-blind, placebo-controlled phase III study. J Clin Oncol. 2011;29:3968-76.

31. Guimbaud R, Louvet C, Ries P, Ychou M, Maillard E, Andre T, Gornet JM, Aparicio T, Nguyen S, Azzedine A, Etienne PL, Boucher E, Rebischung C, Hammel P, Rougier P, Bedenne L, Bouche O. Prospective, randomized, multicenter, phase III study of fluorouracil, leucovorin, and irinotecan versus epirubicin, cisplatin, and capecitabine in advanced gastric adenocarcinoma: a French intergroup (Federation Francophone de Cancerologie
Digestive, Federation Nationale des Centres de Lutte Contre le Cancer, and Groupe Cooperateur Multidisciplinaire en Oncologie) study. J Clin Oncol. 2014;32:3520-6.

32. Yamada Y, Higuchi K, Nishikawa K, Gotoh M, Fuse N, Sugimoto N, Nishina T, Amagai K, Chin K, Niwa Y, Tsuji A, Imamura H, Tsuda M, Yasui H, Fujii H, Yamaguchi K, Hironaka S, Shimada K, Miwa H, Hamada C, Hyodo I. Phase III study comparing oxaliplatin plus $\mathrm{S}-1$ with cisplatin plus $\mathrm{S}-1$ in chemotherapy-naive patients with advanced gastric cancer. Ann Oncol. 2015;26:141-8.

33. Wang YN, Shen KT, Ling JQ, Gao XD, Hou YY, Wang XF, Qin J, Sun YH, Qin XY. Prognostic analysis of combined curative resection of the stomach and liver lesions in 30 gastric cancer patients with synchronous liver metastases. BMC Surg. 2012;12:20.

34. Lordick F, Kang YK, Chung HC, Salman P, Oh SC, Bodoky G, Kurteva G, Volovat C, Moiseyenko VM, Gorbunova V, Park JO, Sawaki A, Celik I, Gotte H, Melezinkova H, Moehler M. Capecitabine and cisplatin with or without cetuximab for patients with previously untreated advanced gastric cancer (EXPAND): a randomised, open-label phase 3 trial. Lancet Oncol. 2013;14:490-9. 